\title{
The climatic suitability for maize cultivation in China
}

\author{
HE QiJin ${ }^{1,2} \&$ ZHOU GuangSheng ${ }^{1,3 *}$ \\ ${ }^{1}$ Chinese Academy of Meteorological Sciences, Beijing 100081, China; \\ ${ }^{2}$ School of Atmospheric Physics, Nanjing University of Information Science and Technology, Nanjing 210044, China; \\ ${ }^{3}$ State Key Laboratory of Vegetation and Environmental Change, Institute of Botany, Chinese Academy of Sciences, Beijing 100093, China
}

Received June 27, 2011; accepted September 9, 2011; published online October 17, 2011

\begin{abstract}
To provide scientific support for planning maize production and designing countermeasures against the effects of climate change on the national maize crop, we analyzed the climatic suitability for cultivating maize across China. These analyses were based on annual climate indices at the Chinese national level; these indices influence the geographical distribution of maize cultivation. The annual climate indices, together with geographical information on the current cultivation sites of maize, the maximum entropy (MaxEnt) model, and the ArcGIS spatial analysis technique were used to analyze and predict maize distribution. The results show that the MaxEnt model can be used to study the climatic suitability for maize cultivation. The eight key climatic factors affecting maize cultivation areas were the frost-free period, annual average temperature, $\geqslant 0^{\circ} \mathrm{C}$ accumulated temperature, $\geqslant 10^{\circ} \mathrm{C}$ accumulated temperature continuous days, $\geqslant 10^{\circ} \mathrm{C}$ accumulated temperature, annual precipitation, warmest month average temperature, and humidity index. We classified climatic zones in terms of their suitability for maize cultivation, based on the existence probability determined using the MaxEnt model. Furthermore, climatic thresholds for a potential maize cultivation zone were determined based on the relationship between the dominant climatic factors and the potential maize cultivation area. The results indicated that the importance and thresholds of main climate controls differ for different maize species and maturities, and their specific climatic suitability should be studied further to identify the best cultivation zones. The MaxEnt model is a useful tool to study climatic suitability for maize cultivation.
\end{abstract}

maize, planting distribution, dominant climatic factor, climatic suitability, maximum entropy (MaxEnt) model

Citation: He Q J, Zhou G S. The climatic suitability for maize cultivation in China. Chin Sci Bull, 2012, 57: 395-403, doi: 10.1007/s11434-011-4807-2

The interaction between vegetation and climate can be divided into the adaptability of vegetation to climate, and the feedback of vegetation on the climate. Usually, major vegetation types respond to major climate types, and each climate type or division is associated with a set of corresponding vegetation types. Thus, the study of climatevegetation classification has drawn increasing attention from botanists, ecologists, climatologists, and geographers $[1,2]$. There have been many studies on the relationships among the crop cultivation system, the distribution of the cultivation area, and climate; and the growth of maize in different climatic divisions of China and the response of maize crops to climate change have attracted particular at-

*Corresponding author (email: gszhou@ cams.cma.gov.cn) tention [3-6]. However, most of these studies have focused on a local area, and few have been conducted at the Chinese national scale. Moreover, the research results vary widely at present, because they are based on data with different temporal scales and dissimilar major factors affecting crop growth. Therefore, planning of crop production and countermeasures to cope with the effects of climate change on the maize crop in China are seriously restricted by the lack of a robust method to analyze the climatic suitability for maize cultivation across China.

Maize is one of the most widely planted crops in the world. Statistics from the Food and Agriculture Organization (FAO) indicated that in 2003, the maize cultivation area worldwide was approx. $1.4268 \times 10^{8} \mathrm{hm}^{2}$, with a total yield of approx. $6.3804 \times 10^{8} \mathrm{t}$. The cultivation area of maize is 
usually less than that of rice and wheat; however, its yield is greater than both. Moreover, it is the field crop with the greatest area of expansion and the most rapid increase in crop yield. China has one of the greatest areas of maize cultivation. The maize cultivation area in China has been approx. $2.453 \times 10 \mathrm{hm}^{2}$ per year since the end of the 20th century, with an annual yield of up to $1.2318 \times 10^{8} \mathrm{t}$, second only to that of the United States of America. Maize is an important source of raw materials for food, feed, products for the fermentation industry, and products for chemical production. It plays a critical role in global food security and national economic development.

The climate is a very important factor in maize production. Global warming is now a reality, and will continue to be so for the foreseeable future [7]. Climate change has resulted in a northward shift and an eastward expansion of the planting boundaries for various maize varieties maturing at different times; early maturing varieties are being replaced by mid- or later-maturing varieties, the plantable area for mid- and later-maturing maize varieties is increasing [8], and the growth period is lengthening in the northwest region [9]. In 2000, the Intergovernmental Panel on Climate Change (IPCC) published a set of scenarios in the Third Assessment Report (Special Report on Emissions ScenariosSRES). The SRES scenarios were constructed to explore future developments in the global environment with special reference to the production of greenhouse gases and aerosol precursor emissions. Among these scenarios, the A2 storyline and scenario family indicate a very heterogeneous world with a continuously increasing global population and regionally oriented economic growth that is more fragmented and slower than those in other storylines, and a $3.5^{\circ} \mathrm{C}$ increase in the global surface air temperature by the end of the 21st century. The B2 storyline and scenario family indicate a world in which the emphasis is on local solutions to economic, social, and environmental sustainability, with a continuously increasing population (but lower than that of A2) and intermediate economic development, and a $2.0^{\circ} \mathrm{C}$ increase in the global surface air temperature by the end of the 21 st century. The results suggested that the maize yield in five major maize production regions of China would decrease under the conditions of the A2 and B2 scenarios [10]. To ensure a sustainably high yield of maize in China under the conditions of climate change, there is an urgent need to understand the effects of global change on maize production and to establish where maize could be planted. The key scientific issue to solve this problem is to identify the major climatic factors affecting maize cultivation regions in China and to classify the areas where the climate is suitable for maize cultivation.

The objectives of this study were (1) to identify the major climatic factors and their thresholds affecting maize cultivation regions in China; and (2) to provide a climate suitability classification for maize cultivation, based on annual climate indices at the Chinese national level. These indices affect the distribution of maize cultivation, and together with information on the geographical distribution of the maize cultivation zone in China, the MaxEnt model, and the ArcGIS spatial analysis technique, they can be used to analyze maize distribution now and in the future.

\section{Materials and methods}

\subsection{Materials}

Information on the geographic distribution of maize cultivation sites in China was obtained from 366 Agricultural Meteorological Observation Stations, and provided by the China Meteorological Administration (Figure 1). Climatic data were provided by the National Meteorological Information Center, China Meteorological Administration.

Climate data are from the Chinese daily climate data set (1971-2000), and include site longitude, latitude, daily mean, maximum, and minimum air temperature, and precipitation. These daily data were interpolated to obtain spatial grid data with $10 \mathrm{~km} \times 10 \mathrm{~km}$ resolution based on methods reported elsewhere $[11,12]$ and a digital elevation model (DEM).

\subsection{Potential climatic factors}

For each crop, its cultivation depends on interactions between thermal and water resources. Annual climate indices from both maize and natural vegetation divisions at the Chinese national level were included in these analyses. These indices influence the distribution of maize cultivation. For this study, 10 potential climatic factors with identical biological significance were selected from these indices to determine major climatic factors affecting the distribution of maize cultivation in China. The potential climatic factors

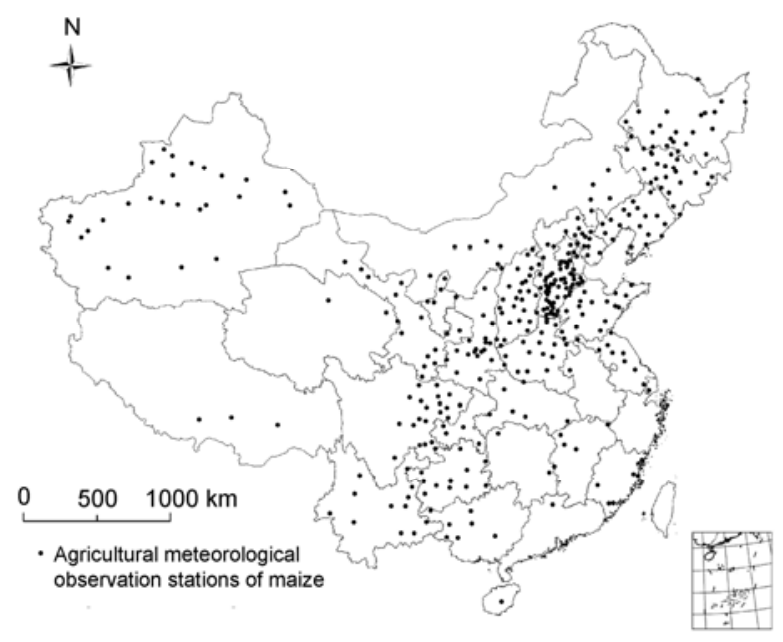

Figure 1 Distribution of maize cultivation sites from Agricultural Meteorological Observation Stations, China Meteorological Administration. 
selected were annual average temperature, $\geqslant 0{ }^{\circ} \mathrm{C}$ accumulated temperature, $\geqslant 10^{\circ} \mathrm{C}$ accumulated temperature, $\geqslant 10^{\circ} \mathrm{C}$ accumulated temperature continuous days, frost-free period, coldest month average temperature, warmest month average temperature, annual range of monthly mean temperature, annual precipitation, and humidity index (Table 1) [13-26].

The frost-free period and $\geqslant 10^{\circ} \mathrm{C}$ accumulated temperature continuous days indicate the thermal resources in a continuous period. Annual average temperature, coldest month average temperature, warmest month average temperature, and annual range of monthly mean temperature indicate the thermal intensity. The extent of thermal accumulation is reflected by the $\geqslant 0^{\circ} \mathrm{C}$ accumulated temperature and $\geqslant 10^{\circ} \mathrm{C}$ accumulated temperature. Annual precipitation and humidity indices are used to evaluate the extent of dry or humid conditions. The higher the moisture index, the more humid the climate.

\subsection{MaxEnt model}

Recently, many kinds of models have been used to simulate the potential distribution of plant species. These models included the ecological models BIOCLIM, BLOMAPPER, DIVA, and DOMAIN, the dynamic simulation model CLIMEX, a generalized additive model (GAM), a generalized linear model (GLM), a genetic algorithm for rule-set prediction (GARP), and MaxEnt [27-31]. Of these, MaxEnt showed the best predictive capacity and was the most precise [32-38], giving the most accurate distribution function based on best entropy. First, the characteristic space, i.e. the known distribution domain of specific plant species, is determined. Next, the restrictive conditions (environmental factors) are identified, and the assemblage of restrictive factors developed. Finally, the relationship between the potential distribution and environmental factors is established [31].

\section{Results and analyses}

\subsection{Applicability of the MaxEnt model}

To validate the applicability of the MaxEnt model to predict the maize cultivation zone in China, $75 \%$ of the total data were selected as the training data subset to construct the MaxEnt model, which is then used to obtain the model parameters. Then, $25 \%$ of the total data set was used to evaluate the applicability of the constructed MaxEnt model. The model required two data sets: the geographic distribution data set of the selected plant species, i.e. the geographic distribution information of maize cultivation sites in China obtained from 366 Agricultural Meteorological Observation Stations; and the national environmental data set, i.e. 10 climatic factors selected from the references of the maize climate division and natural vegetation division at the national Chinese level that influence the distribution of maize cultivation (Table 1).

A receiver operating characteristic (ROC) curve is generally used to evaluate the simulation accuracy of the model [39]. The area below the ROC curve, i.e. the value of the area under the curve (AUC) indicates the predictive accuracy of the model. The value of AUC ranges from 0.5 and 1 , indicating the following degrees of predictive accuracy [40]: 0.50-0.60 (fail), 0.60-0.70 (poor), 0.70-0.80 (fair), 0.800.90 (good), and 0.90-1.0 (excellent). When the values of

Table 1 Potential climatic factors affecting the distribution of maize cultivation in China

\begin{tabular}{|c|c|c|c|}
\hline Climate factor & Calculation method & Explanation & Reference \\
\hline$\geqslant 0^{\circ} \mathrm{C}$ accumulated temperature & Five-day sliding average & Thermal resources suitable for crop farming period & {$[13,14]$} \\
\hline$\geqslant 10^{\circ} \mathrm{C}$ accumulated temperature & Five-day sliding average & $\begin{array}{l}\text { Temperature intensity and durative time during growing } \\
\text { period of warm mate plant or during peak growing period of } \\
\text { cool mate plant }\end{array}$ & {$[15-25]$} \\
\hline $\begin{array}{l}\geqslant 10^{\circ} \mathrm{C} \text { accumulated temperature } \\
\text { continuous days }\end{array}$ & Five-day sliding average & $\begin{array}{l}\text { Growing period of warm mate plant or peak growing period } \\
\text { of cool mate plant }\end{array}$ & [19] \\
\hline Annual average temperature & $\sum_{i=1}^{n} t_{i} / n$ & Annual thermal resources & {$[20]$} \\
\hline Annual precipitation & $\sum_{i=1}^{n} p_{i}$ & Annual water resources & [14] \\
\hline $\begin{array}{l}\text { The coldest month average } \\
\text { temperature }\left(t_{\mathrm{c}}\right)\end{array}$ & Average temperature of January & The overwinter condition for crop & [14] \\
\hline $\begin{array}{l}\text { The warmest month average } \\
\text { temperature }\left(t_{\mathrm{w}}\right)\end{array}$ & Average temperature of July & The high temperature condition for warm mate plant & [14] \\
\hline $\begin{array}{l}\text { Annual range of monthly mean } \\
\text { temperature }\end{array}$ & Temperature difference $\left(t_{\mathrm{w}}-t_{\mathrm{c}}\right)$ & $\begin{array}{l}\text { Variation range of monthly mean temperature during one } \\
\text { year }\end{array}$ & [14] \\
\hline Humidity index & $\begin{array}{l}\text { The ratio of precipitation and } \\
\text { potential evapotranspiration }\end{array}$ & Dry or humid climate condition & {$[14,26]$} \\
\hline
\end{tabular}


AUC are more than 0.75 , the constructed model is applicable. The higher the AUC value, the more accurate the predictions of the constructed model [41].

The AUC of the constructed model based on the potential climatic factors affecting the distribution of the maize cultivation zone was 0.818 . This value indicated that the constructed model had "good" predictive accuracy, and therefore, that it was suitable for predicting the geographic distribution of maize cultivation in China.

\subsection{Major climatic factors affecting the geographic distribution of maize cultivation in China}

The 10 potential climatic factors were derived from the literature; however, their contributions to the geographic distribution of maize cultivation have not been evaluated. To construct the MaxEnt model with the greatest AUC, the contributions made by the potential climatic factors to the geographic distribution of maize cultivation were quantitatively evaluated at the Chinese national level. As a result, quantitative contributions of the major climatic factors to distribution were determined. Figure 2 shows the contribution ratio of the potential climatic factors to the geographic distribution of maize cultivation from the Jackknife module, based on the constructed MaxEnt model. In terms of their quantitative contribution to distribution, the climatic factors were ranked in the following order: frost-free period $>$ annual average temperature $\geqslant 0^{\circ} \mathrm{C}$ accumulated temperature $\geqslant 10^{\circ} \mathrm{C}$ accumulated temperature continuous days $\geqslant 10^{\circ} \mathrm{C}$ accumulated temperature $>$ annual precipitation $>$ warmest month average temperature $>$ humidity index $>$ coldest month average temperature $>$ annual range of monthly mean temperature.

Eight major climatic factors were identified based on their ratio of contribution to the geographic distribution of maize cultivation in China. This ratio was calculated from the Jackknife module, based on the constructed MaxEnt model. The eight major climate factors were frost-free period, annual average temperature, $\geqslant 0^{\circ} \mathrm{C}$ accumulated temperature, $\geqslant 10^{\circ} \mathrm{C}$ accumulated temperature continuous days, $\geqslant 10^{\circ} \mathrm{C}$ accumulated temperature, annual precipitation, the warmest month average temperature, and the humidity index. The contribution from these eight major climatic factors is approx. $91.5 \%$.

\subsection{Classification of climatic zones in terms of suitability for maize cultivation in China}

The climatic zones were classified in terms of their suitability for maize cultivation in China based on the existence probability $(p)$ derived from the MaxEnt model. The MaxEnt model was constructed from the eight major climatic factors selected. The existence probability from the MaxEnt model ranges from 0 to 1 . Based on statistical principles, low probability events take place when the existence probability is less than 0.05 . Therefore, a region with an existence probability less than 0.05 would not be suitable for maize cultivation. Together with the description of probability from the Fourth Assessment Report of the IPCC, the standard values of existence probability $(p)$ for the climate suitability classification are: $p<0.05$ (unsuitable area), $0.05 \leqslant p<0.33$ (less suitable area), $0.33 \leqslant p<0.66$ (suitable area), and $p \geqslant 0.66$ (optimum area).

Figure 3 shows climate suitability classification of maize cultivation zones in China. Approx. $4 \%$ of the total land area is "optimum", approx. $25 \%$ is "suitable", approx. $40 \%$ is "less suitable", and approx. $31 \%$ is "unsuitable". Thirtyone provinces show strong suitability for growing maize. However, the effects of climate on the maize cultivation zone result in a narrow belt from the northeast to southwest

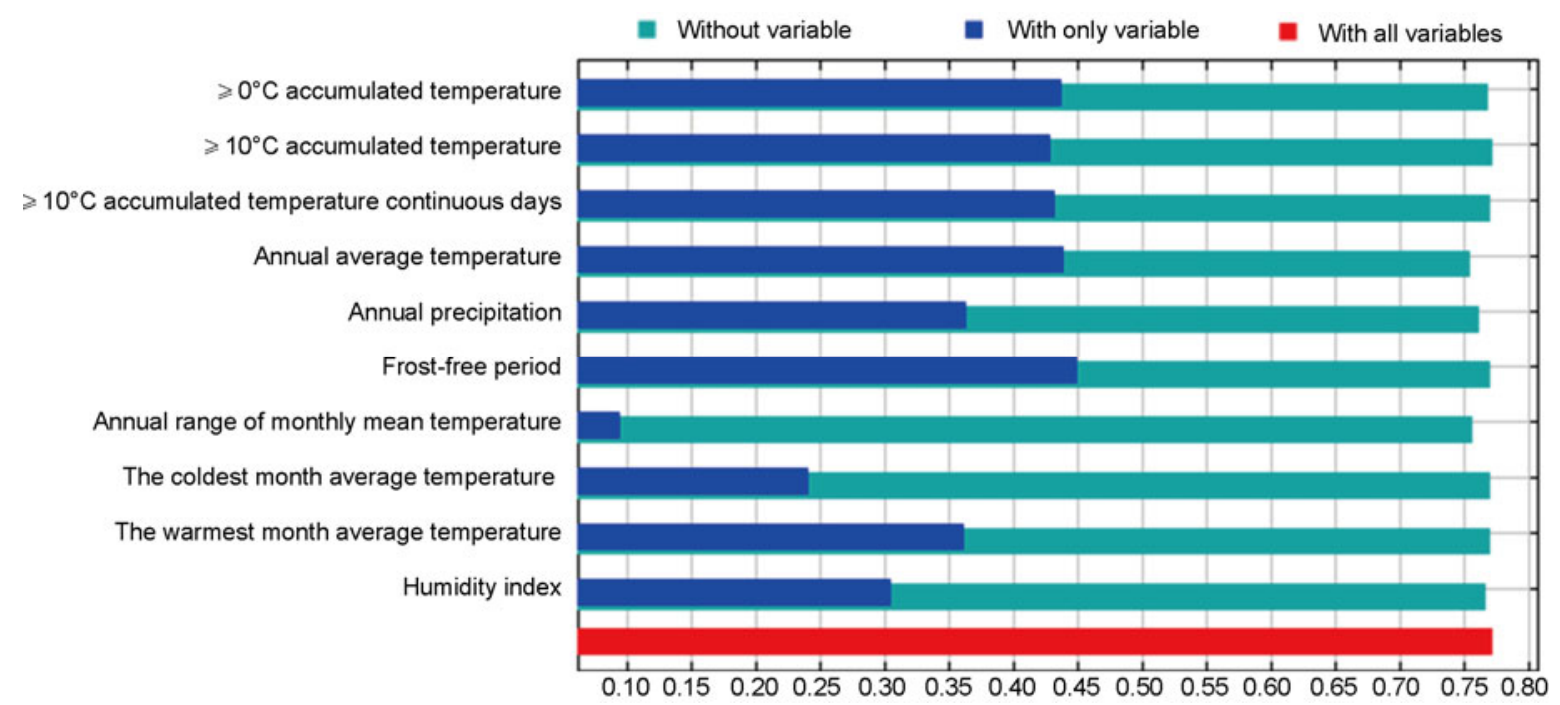

Figure 2 Contribution ratio of potential climatic factors indicating their contribution to distribution of maize cultivation in China. Ratio was calculated from the Jackknife module based on the constructed MaxEnt model. 


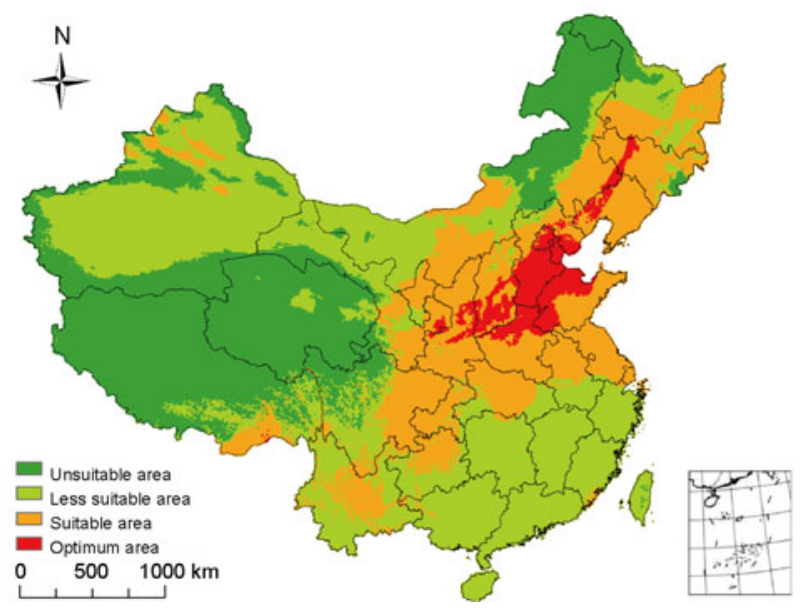

Figure 3 Climate suitability classifications of maize cultivation zones in China.

(Figure 3). The major maize production regions are in Heilongjiang, Jilin, Liaoning, Hebei, Henan, Shanxi, Shandong, Shaanxi, Hubei, Sichuan, and Yunnan provinces, although different provinces have different climates (Table 2). The optimum area for maize cultivation, which includes Jilin, Liaoning, Hebei, Shanxi, Shaanxi, Gansu and Henan provinces, has mainly a middle- and cold-temperate semiarid, subhumid climate, with appropriate thermal and precipitation conditions that meet the growth demands of maize without causing high temperature damage. The suitable area, which includes Heilongjiang Province; the Inner Mongolia Autonomous Region (Inner Mongolia for short); the southern Tibetan Plateau; Shandong, Jiangsu, Henan, Anhui, Hubei, Sichuan, Yunnan provinces, and Chongqing, belongs to the warm temperate subhumid climate, and has appropriate temperature and irrigation facilities. The less suitable area includes the Xinjiang Uygur Autonomous Region (Xinjiang for short); Inner Mongolia; most of Gansu Province; Zhejiang, Jiangxi, Guizhou, Hunan, Guangdong, Fujian, Hainan, Taiwan provinces, and Guangxi Zhuang Autonomous Region (Guangxi for short). There is sufficient sunshine, a large day/night temperature difference, and less precipitation in Xinjiang, Inner Mongolia, and most parts of Gansu Province, where maize could not be grown without irrigation. The other less suitable area has excessive rainfall and very high temperatures; here the main production crop is paddy rice followed by maize. The unsuitable area, which includes Qinghai Province; most of the Xizang (Tibet) Autonomous Region (Xizang for short); northern and southern parts of Xinjiang; the northern part of Heilongjiang Province; the northern part of Inner Mongolia; and the northwestern part of Sichuan Province, has a cold, dry climate.

The geographical ranges of the "optimum", "suitable", "less suitable", and "unsuitable" areas presented in this study almost correspond with the results from the maize climate division of China [42]. However, the optimum area in this study shifts slightly southward, and it includes most parts of Henan and Shandong provinces. In addition, most of the inland regions in northwest China change from "optimum" to "suitable" or "less suitable" areas; and the western part of Inner Mongolia changes from an "unsuitable" to a "less suitable" or "suitable" area. The reason for these changes is that the current maize division is based on growth season, precipitation, and yield, while global warming and improvement of maize varieties will result in a prolonged growth season and enhanced drought resistance. As

Table 2 General view of climate suitability of the maize planting zone in China

\begin{tabular}{|c|c|c|c|c|}
\hline Item & Optimum area & Suitable area & Less suitable area & Unsuitable area \\
\hline Frost-free period (d) & $176-316$ & $147-366$ & $62-366$ & $61-366$ \\
\hline Annual average temperature $\left({ }^{\circ} \mathrm{C}\right)$ & $4.7-19.2$ & $2.9-22.1$ & $-0.5-24.9$ & $-10.2-21.0$ \\
\hline $\begin{array}{l}\geqslant 0^{\circ} \mathrm{C} \text { accumulated temperature } \\
\left({ }^{\circ} \mathrm{C} \mathrm{d}\right)\end{array}$ & $3336.9-6507.3$ & 2047.0-7179.9 & $1419.4-7980.7$ & $45.0-6915.5$ \\
\hline $\begin{array}{l}\geqslant 10^{\circ} \mathrm{C} \text { accumulated temperature } \\
\text { continuous days }(\mathrm{d})\end{array}$ & $166-270$ & $125-309$ & $82-310$ & $11-299$ \\
\hline $\begin{array}{l}\geqslant 10^{\circ} \mathrm{C} \text { accumulated temperature } \\
\left({ }^{\circ} \mathrm{C} \mathrm{d}\right)\end{array}$ & 2913.9-6146.0 & $1320.3-7164.3$ & $291.6-7980.7$ & $1.5-6772.0$ \\
\hline Annual precipitation (mm) & $508.7-812.7$ & $125.3-1708.3$ & $53.3-2203.3$ & $52.0-2198.6$ \\
\hline $\begin{array}{l}\text { The warmest month average } \\
\text { temperature }\left({ }^{\circ} \mathrm{C}\right)\end{array}$ & $22.1-28.6$ & $13.5-30.8$ & $8.7-29.3$ & $-0.4-26.8$ \\
\hline Humidity index & $0.05-0.14$ & $0.02-0.27$ & $0.01-0.50$ & $0.01-3.67$ \\
\hline Main distribution & $\begin{array}{l}\text { most parts of Hebei, Shanxi, } \\
\text { Shandong and Henan } \\
\text { provinces; Beijing and } \\
\text { Tianjin; small parts of Jilin, } \\
\text { Liaoning, Shaanxi and } \\
\text { Gansu provinces }\end{array}$ & $\begin{array}{l}\text { Northeast Plain located in the } \\
\text { east of Da Hinggan Mountains, } \\
\text { North China Plain, Loess Plat- } \\
\text { eau, Sichuan basin, middle and } \\
\text { lower reaches of Yangtze } \\
\text { River; parts of Yunan-Guizhou } \\
\text { Plateau, Junggar basin and } \\
\text { South Tibetan Plateau }\end{array}$ & $\begin{array}{l}\text { north Heilongjiang } \\
\text { Province; West Inner } \\
\text { Mongolia; most of } \\
\text { Xinjiang, Gansu and } \\
\text { Yunnan provinces; } \\
\text { south Sichuan Province; } \\
\text { South Yangtze River }\end{array}$ & $\begin{array}{l}\text { northern part of } 50^{\circ} \mathrm{N} \text {; East } \\
\text { Inner Mongolia; most parts } \\
\text { of Qinghai-Tibet Plateau and } \\
\text { western Sichuan Plateau; } \\
\text { northern and southern part } \\
\text { of Xinjiang }\end{array}$ \\
\hline
\end{tabular}


a result, the optimum maize cultivation zone shifts southward. Gao et al. [43] pointed out that annual precipitation in the arid and semiarid transitional region of northwestern China has significantly decreased over the last 50 years, especially in the last decade. Aridification might increase in the future as temperature and soil evaporation rates increase. Thus, a warm-dry climate would result in the "optimum" areas in most of the inland region of northwest China changing to "suitable" or "less suitable" areas. With global warming, the western part of Inner Mongolia would change from being an "unsuitable" to a "suitable" or "less suitable" area.

The climate suitability classifications of the spring and summer maize cultivation zones are shown in Tables 3 and 4 , respectively. These classifications are based on geographic distribution information from 216 spring maize cultivation sites and 188 summer maize cultivation sites from the Agricultural Meteorological Observation Stations, China Meteorological Administration, and the Chinese daily climate data set (1971-2000) with $10 \mathrm{~km} \times 10 \mathrm{~km}$ spatial resolution.

There are variations in the importance of major climatic factors affecting different maize varieties and their thresholds (Tables 2-4). By comparison, the climate suitability classification of the maize cultivation zones determined in this study almost match the current distribution of maize cultivation [42], and the northern border of the spring maize cultivation zone is consistent with the result reported by Zhang et al. [44]. These findings indicate that climate suitability should be studied for different maize varieties and maturities to obtain accurate crop distribution information. Our studies on the climate suitability of spring and summer maize show that the MaxEnt model can be used to simulate the climate suitability of the maize cultivation zone in China.

\subsection{Analyses of thresholds of major climatic factors affecting the maize cultivation zone in China}

Climatic differences restrict crop growth and development, and affect the distribution of the crop cultivation area [45]. Eight major climatic factors affecting the distribution of cultivated maize were identified in this study, based on the MaxEnt model (see 2.2). The thresholds of major climatic factors affecting the maize cultivation zone can be given in terms of climate suitability classifications and the relationship between the distribution of the maize cultivation area (indicated by the number of grids) and the major climatic factors. The thresholds of major climatic factors affecting the distribution of maize cultivation areas are as follows (Figure 4(a)-(h)): frost-free period $\geqslant 62 \mathrm{~d}$, annual average temperature -0.51 to $24.9^{\circ} \mathrm{C}, \geqslant 0{ }^{\circ} \mathrm{C}$ accumulated temperature 1419.4 to $7980.7^{\circ} \mathrm{C} \cdot \mathrm{d}, \geqslant 10^{\circ} \mathrm{C}$ accumulated temperature continuous days 82 to $310 \mathrm{~d}, \geqslant 10^{\circ} \mathrm{C}$ accumulated temperature 291.57 to $7980.7^{\circ} \mathrm{C} \cdot \mathrm{d}$, annual precipitation 53.3 to $2203.3 \mathrm{~mm}$, warmest month average temperature 8.7 to $30.8^{\circ} \mathrm{C}$, and humidity index 0.01 to 0.50 .

\section{Discussion and conclusion}

In this study, 10 potential climatic factors affecting the maize cultivation zone in China were examined. These factors, which were based on annual climate indices from references at the Chinese national level, together with information about the distribution of maize cultivation, were

Table 3 General view of climate suitability of the spring maize cultivation zone in China

\begin{tabular}{|c|c|c|c|c|}
\hline Item & Optimum area & Suitable area & Less suitable area & Unsuitable area \\
\hline$\geqslant 0^{\circ} \mathrm{C}$ accumulated temperature $\left({ }^{\circ} \mathrm{C} \mathrm{d}\right)$ & $3035.9-4244.1$ & $2214.0-7179.8$ & $1500.4-7980.7$ & $44.85-7247.7$ \\
\hline$\geqslant 10^{\circ} \mathrm{C}$ accumulated temperature $\left({ }^{\circ} \mathrm{C} \mathrm{d}\right)$ & $2559.2-3814.3$ & $1403.0-7164.3$ & $321.8-7980.7$ & $1.54-7150.8$ \\
\hline Frost-free period (d) & $164-248$ & $157-366$ & $62-366$ & $61-366$ \\
\hline $\begin{array}{l}\text { The warmest month average } \\
\text { temperature }\left({ }^{\circ} \mathrm{C}\right)\end{array}$ & $20.6-25.1$ & $13.5-30.8$ & $8.7-29.6$ & $-0.42-28.3$ \\
\hline Annual average temperature $\left({ }^{\circ} \mathrm{C}\right)$ & $3.8-11.5$ & $2.9-22.1$ & $-1.5-24.9$ & $-10.2-22.0$ \\
\hline Annual precipitation (mm) & $383.0-811.1$ & $126.6-1749.7$ & $53.3-2203.3$ & $52.0-2076.3$ \\
\hline Humidity index & $0.08-0.20$ & $0.02-0.28$ & $0.01-0.49$ & $0.01-3.67$ \\
\hline Main distribution & $\begin{array}{l}\text { western part of Jilin } \\
\text { and Liaoning prov- } \\
\text { inces; parts of Inner } \\
\text { Mongolia; Beijing; } \\
\text { Hebei, Shanxi, } \\
\text { Shaanxi and Gansu } \\
\text { provinces }\end{array}$ & $\begin{array}{l}\text { Liaoning, Hebei, Shandong } \\
\text { provinces and Ningxia Hui } \\
\text { Auonomous Region (Ningxia for } \\
\text { short); Beijing, Tianjin, most parts } \\
\text { of Heilongjiang, Jilin, Shanxi, } \\
\text { Henan and Shaanxi provinces; } \\
\text { south Gansu Province; small } \\
\text { parts of Inner Mongolia, Xinjiang, } \\
\text { Sichuan basin, Chongqing, Yunnan, } \\
\text { Jiangsu, Hubei, Hunan provinces and } \\
\text { southern Tibetan Plateau }\end{array}$ & $\begin{array}{l}\text { Northeast China except } \\
\text { north Heilongjiang } \\
\text { and east Jilin provinces; } \\
\text { North China except east } \\
\text { Inner } \\
\text { Mongolia; East China, } \\
\text { Middle China and South } \\
\text { China; east Sichuan } \\
\text { Province, most part of } \\
\text { Xinjiang and southern } \\
\text { Tibetan Plateau }\end{array}$ & $\begin{array}{l}\text { north part of } 50^{\circ} \mathrm{N} \text {, } \\
\text { east Inner Mongolia, } \\
\text { Qinghai-Tibet Plateau, } \\
\text { western Sichuan } \\
\text { Plateau; part of } \\
\text { Xinjiang }\end{array}$ \\
\hline
\end{tabular}


Table 4 General view of climate suitability of the summer maize cultivation zone in China

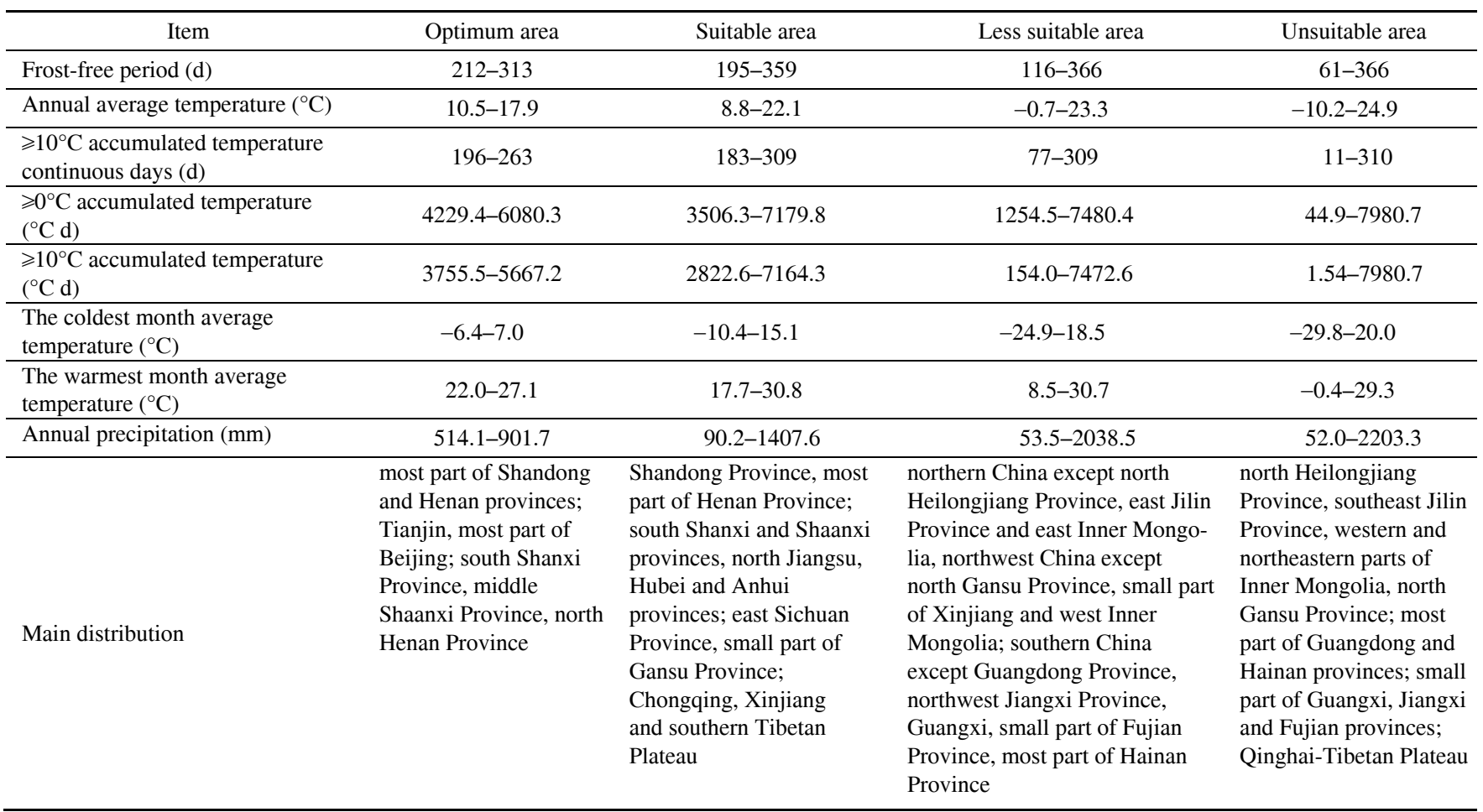

used to evaluate the applicability of the MaxEnt model for simulating the maize cultivation zone. The results indicated that the MaxEnt model had "good" predictive accuracy $(\mathrm{AUC}=0.818)$ in terms of the relationship between the distribution of maize cultivation and climate. This indicated that the MaxEnt model can be used to predict geographic distribution, to reveal major climatic factors, and to classify various climates in terms of their suitability as maize cultivation zones in China.

The thresholds of eight major climatic factors affecting the distribution of maize cultivation in China were calculated as follows: frost-free period $\geqslant 62 \mathrm{~d}$, annual average temperature -0.51 to $24.9^{\circ} \mathrm{C}, \geqslant 0^{\circ} \mathrm{C}$ accumulated temperature 1419.4 to $7980.7^{\circ} \mathrm{C} \cdot \mathrm{d}, \geqslant 10^{\circ} \mathrm{C}$ accumulated temperature continuous days 82 to $310 \mathrm{~d}, \geqslant 10^{\circ} \mathrm{C}$ accumulated temperature 291.6 to $7980.7^{\circ} \mathrm{C} \cdot \mathrm{d}$, annual precipitation 53.3 to $2203.3 \mathrm{~mm}$, warmest month average temperature 8.7 to $30.8^{\circ} \mathrm{C}$, and humidity index, 0.01 to 0.50 .

Based on the major climatic factors and the existence probability from the MaxEnt model, we classified climate zones in terms of their suitability for maize cultivation. The geographical ranges of optimum area, suitable area, less suitable area, and unsuitable area shown in this study almost match the current distribution of maize cultivation in China [42]. The optimum area was approx. $4 \%$ of the total land area in China; the suitable area approx. 25\%; the less suitable area approx. $40 \%$; and the unsuitable area approx. $31 \%$. Because of global warming and improvement in maize vari- eties, the optimum area in this study shifts slightly southward and includes most of Henan and Shandong provinces. Most of the inland regions in the northwest of China change from being optimum areas into being suitable or less suitable, and the western part of Inner Mongolia changes from being an unsuitable area into a less suitable or suitable area. These data could provide scientific support for planning maize production and countermeasures to cope with climate change in China.

Moreover, the results of this study indicate that there are variations in the importance and the thresholds of major climatic factors affecting different maize varieties. These findings suggest that the climate suitability of different maize varieties and maturities should be studied to obtain accurate information on the areas of crop cultivation. Our studies on the climate suitability of spring maize and summer maize show that the MaxEnt model can be used to classify climatic zones according to their suitability for cultivation of spring and summer maize in China.

It should be noted that the distribution of maize cultivation in China depends not only on climate, socio-economic conditions, and local production technologies, but also on soil type, geographic characteristics, crop varieties, human activity, and so on [46]. Therefore, for maize cultivation, one should consider the overall impact, especially in relation to its yield and economic value. In this study, we have not considered the effects of agro-meteorological disasters, or differences in maize varieties and maturity. These aspects should be further studied in future research. 

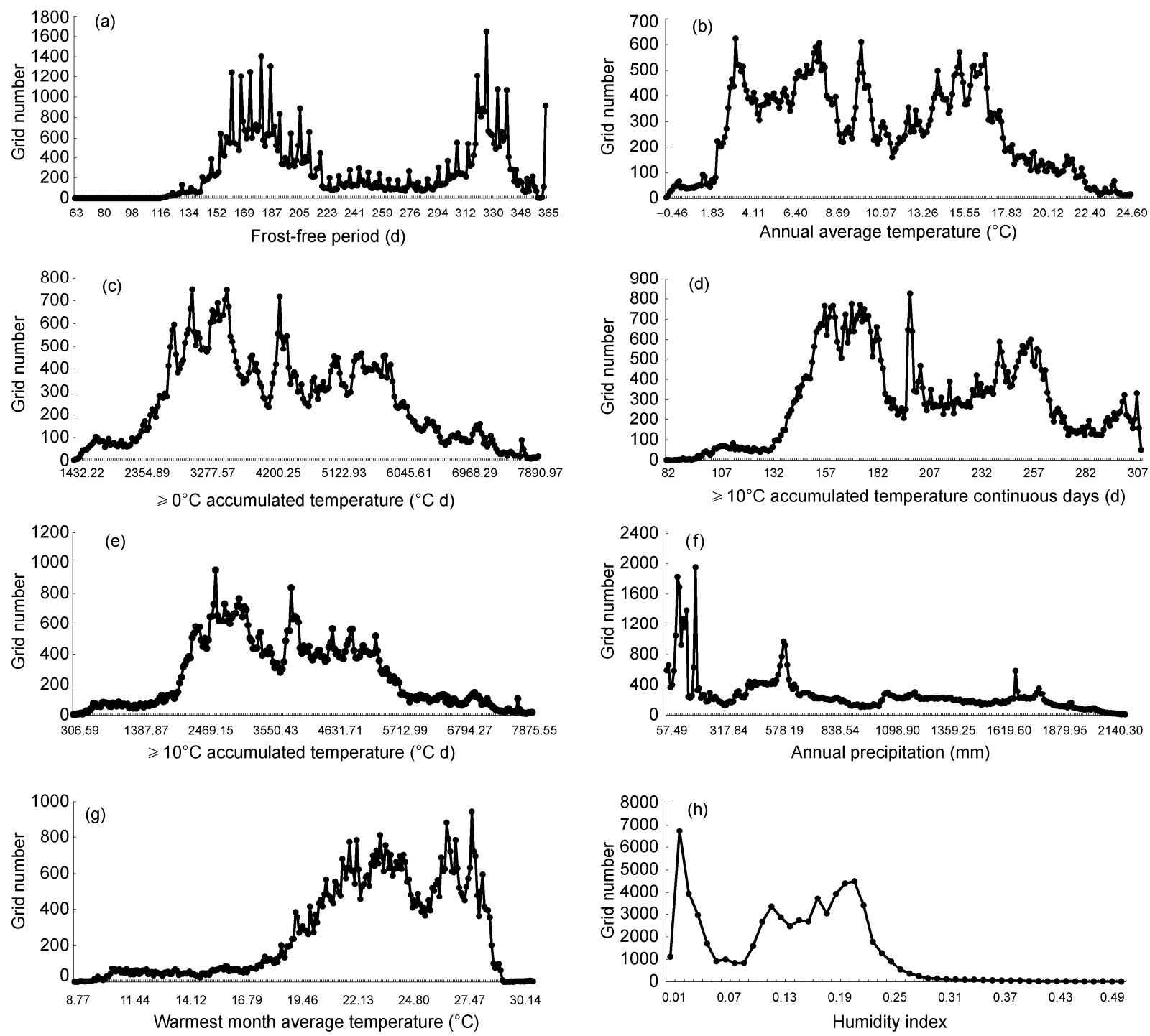

Figure 4 Relationships between distribution of maize cultivation area in China and major climatic factors. (a) Frost-free period; (b) annual average temperature; (c) $\geqslant 0^{\circ} \mathrm{C}$ accumulated temperature; $(\mathrm{d}) \geqslant 10^{\circ} \mathrm{C}$ accumulated temperature continuous days; (e) $\geqslant 10^{\circ} \mathrm{C}$ accumulated temperature; (f) annual precipitation; (g) warmest month average temperature; (h) humidity index.

This work was supported by the National Basic Research Program of China (2010CB951303), the Special Fund for Agro-scientific Research in the Public Interest (200903003) and the Basic Operation Cost of China Meteorological Administration (CMA).

1 Li Y Y, Zhang X S, Zhou G S, et al. Quantitative relationships between vegetation and several pollen taxa in surface soil from North China. Chin Sci Bull, 2000, 45: 1519-1523

2 Zhou G S, Wang Y H. Global change and climate-vegetation classification. Chin Sci Bull, 2000, 45: 577-584

3 Liu M C, Deng Z Y, Li Q Z, et al. The suitable planting division of corn in Gansu (in Chinese). Agr Res Arid Areas, 2005, 23: 112-117

4 Yu W D, Chen H L. Study on precise comprehensive agricultural climate regional planning of summer maize in Henan Province (in Chinese). Meteorol Environ Sci, 2010,33: 14-19

5 He S F, Dong Z D, Zhan K H, et al. Study on plotting out double maturation cropping regions on wheat and corn in Henan Province (in Chinese). J Nat Resour, 2009, 24: 1115-1123

6 Li Z G, Yang P, Zhou Q B, et al. Research on spatiotemporal pattern of crop phenological characteristics and cropping system in North
China based on NDVI time series data (in Chinese). Acta Ecol Sin, 2009, 29: 6216-6226

7 Yao F M, Qin P C, Zhang J H, et al. Uncertainties in assessing the effect of climate change on agriculture using model simulation and uncertainty processing methods. Chin Sci Bull, 2011, 56: 729-737

8 Zhao J F, Yang X G, Liu Z J. Influence of climate warming on serious low temperature and cold damage and cultivation pattern of spring maize in Northeast China (in Chinese). Acta Ecol Sin, 2009, 29: 6544-6551

9 Wang R Y, Zhang Q, Wang Y, et al. Response of corn to climate warming in arid areas in Northwest China. Acta Bot Sin, 2004, 46: $1387-1392$

$10 \mathrm{Hu}$ Y N. Impacts of climatic change to maize production and adaptability analysis in China (in Chinese). Master's Thesis. Beijing: Chinese Academy of Agricultural Sciences, 2008

11 Thornton P E, Running S W, White M A. Generating surfaces of daily meteorological variables over large regions of complex terrain. J Hydrol, 1997, 190: 214-251

12 Liu Y, Chen P Q, Zhang W, et al. A spatial interpolation method for surface air temperature and its error analysis (in Chinese). Chin J Atmos Sci, 2006, 31: 146-152 
13 Office of Agricultural Regionalization in Hebei Province, Hebei Province Meteorological Administration. Agricultural Climate and Its Generalization in Hebei Province (in Chinese). Beijing: China Meteorological Press, 1988

14 Weng E S, Zhou G S. Defining plant functional types in China for global change studies (in Chinese). Acta Phytoecol Sin, 2005, 29: 81-97

15 Deng Z Y. Analysis of climatic adaptation of maize planting and its regionalization (in Chinese). Chin J Agrometeorol, 1983, 1: 23-28

16 Li J Z, Liu D H. Maize favorable planting regionalization in Heilongjiang province (in Chinese). Chin J Agrometeorol, 1983, 1: 6-10

17 Xu D Y. Agricultural Climate Resource and Generalization in Xinjiang Uygur Autonomous Region (in Chinese). Beijing: China Meteorological Press, 1989

18 Liu D, Du C Y, Yu C L. Ecological adaptability evaluation and planting division of maize in Heilongjiang Province (in Chinese). J Maize Sci, 2009, 17: 160-163

19 Lü X, Zhang W, Hu C H, et al. Study on the integrated evaluation of the advantages of climatic ecological factors in maize-growing regions (in Chinese). Arid Zone Res, 2005, 22: 387-390

20 Yang Z Y. A Study on division of maize growing areas in Shanxi province (in Chinese). J Shanxi Agr Univ, 2005, 25: 223-227

21 Zhao J, Chen H. The fuzzy clustering of agricultural regionalization about the maize's cultivation in Xinjiang (in Chinese). J Huangshan Univ, 2007, 9: 6-8

$22 \mathrm{Xu} \mathrm{G} \mathrm{L.} \mathrm{Ecological} \mathrm{regionalization} \mathrm{of} \mathrm{maize} \mathrm{planting} \mathrm{in} \mathrm{Shanxi}$ Province (in Chinese). Shanxi Agr Univ Res, 1990, 10: 194-200

23 Liu M C, Deng Z Y, Li Q Z, et al. The suitable planting division of corn in Gansu (in Chinese). Agr Res Arid Areas, 2005, 23: 112-117

24 Tang H Y, Niu B L. Climate division of spring maize based on GIS technology in Xing'an League, Inner Mongolia (in Chinese). Chin Agr Sci Bull, 2009, 25: 447-450

25 Chen Y X, Liu W, Li J Y. Climatic regionalization of maize planting in Ningcheng county (in Chinese). Inner Mongolia Agr Sci Tech, 2009, 3: 98-99

26 Zhang X S, Yang D A, Ni W G. The potential evapotranspiration (PE) index for vegetation and vegetation-climatic classification (III): An introduction of main methods and PEP program (in Chinese). Acta Phytoecol Geobot Sin, 1993, 17: 97-109

27 Kriticos D, Randall R. A comparison of systems to analyse potential weed distributions. In: Grove R H, Panetta F D, Virtue J G, eds. Weed Risk Assessment. Australia: CSRIO Publishing, 2001. 61-79

28 Guisan A, Thuiller W. Predicting species distribution: Offering more than simple habitat models. Ecol Lett, 2005, 8: 993-1009

29 Elith J, Graham C H, Anderson R P, et al. Novel methods improve prediction of species' distribution from occurrence data. Ecography, 2006, 29: 129-151

30 Sun W T, Liu Y T. Research progress of risk analysis of biological invasion (in Chinese). Chin Agr Sci Bull, 2010, 26: 233-236

31 Phillips S J, Dudik M, Schapire R E. A maximum entropy approach to species distribution modeling. Proceedings of the Twenty-First International Conference on Machine Learning. New York: ACM Press, 2004. 655-662

32 Wang Y S, Xie B Y, Wan F H, et al. Potential geographic distribution of Radopholus similis in China (in Chinese). Sci Agr Sin, 2007, 40: 2502-2506

33 Giovanelli J G R, Haddad C F B, Alexandrino J. Predicting the potential distribution of the alien invasive American bullfrog (Lithobates catesbeianus ) in Brazil. Biol Invasions, 2008, 10: 585590

34 Moffett A, Shackelford N, Sarkar S. Malaria in Africa: Vector species' niche models and relative risk maps. PLoS ONE, 2007, 2: e824

35 Saatchi S, Buermann W, Steege H T, et al. Modeling distribution of Amazonian tree species and diversity using remote sensing measurements. Remote Sens Environ, 2008, 112: 2000-2017

36 Cao X F, Qian G L, Hu B S, et al. Prediction of potential suitable distribution area of Flaveria bidentis in China based on niche models (in Chinese). Chin J Appl Ecol, 2010, 21: 3063-3069

37 Yang B, Xue Y G, Tang X F, et al. Predicting potential geographic distribution of Eupatorium odoratum in China (in Chinese). Plant Protect, 2009, 35: 70-73

$38 \mathrm{Wu}$ W H, Li M Y. Methods for predicting potential habitat of Bursaphelenchus xylophilus based on Ecological Niche Model (in Chinese). For Invent Plan, 2009, 34: 33-38

39 Hanley J A, McNeil B J. The meaning and use of the area under a Receiver Operating Characteristic (ROC) curve. Radiology, 1982, 143: 29-36

40 Swets K A. Measuring the accuracy of diagnostic systems. Science, 1988, 240: 1285-1293

41 Elith J. Quantitative methods for modeling species habitat: Comparative performance and an application to Australian plants. In: Ferson S, Burgman M, eds. Quantitative Methods for Conservation Biology. New York: Springer, 2002. 39-58

42 Cooperative Group of Agriculture, Forestry and Crop Regionalization in China. Climatic Regionalization of Agriculture, Forestry and Crop in China (in Chinese). Beijing: China Meteorological Press, 1987

43 Gao R, Zhang Y X, Shi Y Y, et al. Analysis of climatic change characteristics and impact on grain yield in the northwest arid and semiarid transition region in the recent 50 years (in Chinese). J Anhui Agr Sci, 2009, 37: 6493-6519

44 Zhang J P, Wang C Y, Yang X G, et al. Impact forecast of future climate change on maize water requirement in three provinces of Northeast China (in Chinese). Trans CSAE, 2009, 25: 50-55

45 Li S K, Hou G L, Zheng J F, et al. Agricultural Climatic Resource and Agricultural Climatic Regionalization in China (in Chinese). Beijing: Science Press, 1988

46 Li R P, Zhou G S, Wang Y. Responses of soil respiration in nongrowing seasons to environmental factors in a maize agroecosystem, Northeast China. Chin Sci Bull, 2010, 55: 2723-2730

Open Access This article is distributed under the terms of the Creative Commons Attribution License which permits any use, distribution, and reproduction in any medium, provided the original author(s) and source are credited. 